\title{
Theoretical Conformational Analysis on Silk Fibroin Model Polypeptide with Ala-Gly Repeated Sequence
}

\author{
Masahito OKA ${ }^{\dagger}$, Yoshihiro BABA, Akihiro Kagemoto, \\ and Akio NAKAJIMA* \\ Departments of General Education and * Applied Chemistry, \\ Osaka Institute of Technology, Omiya, \\ Asahi-ku, Osaka 535, Japan
}

(Received September 8, 1989)

\begin{abstract}
Theoretical conformational analysis was carried out for Ac-(Ala-Gly) ${ }_{12}-\mathrm{NHMe}$, which was a model polypeptide of Bombyx mori silk fibroin, using ECEPP and the conformational energy minimization procedure. The hypothesis on the interaction in polypeptide molecules was also used for the analysis. Calculated results showed that right-handed $\alpha$-helix and left-handed $\beta^{4.6}$-helix were the lowest-energy and 2 nd low-energy conformations, respectively. Several stable conformations, which were related to the already proposed model structures of silk fibroin, were also found in the theoretically obtained conformational ensemble of Ac-(Ala-Gly) ${ }_{12}-\mathrm{NHMe}$.

KEY WORDS Conformational Analysis / ECEPP / Poly(Ala-Gly) / Silk Fibroin / Helical Structure / $\beta$-Helix /
\end{abstract}

The native conformation of peptides and proteins is uniquely decided by their aminoacid sequences. By change of temperature, $\mathrm{pH}$ and ionic strength, the native conformation is transformed to the other stable conformation. This means that the ensemble of stable conformations of peptide and proteins is decided by their amino-acid sequences and that their relative stabilities are changed by the given environment. So, it is very important to know the relation between the relative stabilities of conformations and the amino-acid sequences of peptides and proteins as a primary step for recognizing the biological functions in molecular level.

Helical conformations of poly(Val-ProGly-Gly) were theoretically analyzed by the molecular force field method as an elastinmodel polypeptide. ${ }^{1}$ The $\gamma$-helix, which is essentially different from the well-known $\alpha$-and $\beta$-helices and $\beta$-sheet structure, was proposed

$\dagger$ To whom all correspondence should be addressed. as a model conformation of elastin. Helical conformations of poly(L-Ala-D-Ala) were also theoretically analyzed, and the relative stabilities of $\alpha$-and $\beta$-helices were shown as a function of conformational energy. ${ }^{2}$ It is shown that a right-handed $\beta^{4.6}$-helix is the most stable helical conformation and that several $\beta^{6}$-helices are also stable helical conformations. These results indicate that conformational stabilities of polypeptides essentially depend on the amino-acid sequences for two cases of the model polypeptides composed of repeated Val-Pro-Gly-Gly and L-Ala-D-Ala sequences.

Bombyx mori silk fibroin has repeated sequences composed of an alternation of Gly residue with two thirds Ala and one third Ser, i.e., Ala-Gly-Ala-Gly-Ser-Gly, and takes two structures known as silk I and silk II forms depending on the given environments such as solvent, temperature and existence of stress. ${ }^{3,4}$ It is known that silk II structure corresponds 
to the $\beta$-sheet structure, however, silk I structure has not been clearly decided yet because of the difficulty to obtain an oriented sample for X-ray crystallography.

In this paper, the repeated sequence Ala-Gly-Ala-Gly-Ser-Gly of Bombyx mori silk fibroin is simplified as a model sequence Ala-Gly. This treatment is based on the following experimental and theoretical results. (1) Silk fibroin with silk I structure and poly(Ala-Gly) with form II present the same $\mathrm{X}$-ray diffraction pattern, ${ }^{5,6}$ and the same ${ }^{13} \mathrm{C}$ chemical shifts of $\mathrm{C}^{\alpha}, \mathrm{C}^{\beta}$ and $\mathrm{C}=\mathrm{O}$ of Ala residue and $\mathrm{C}^{\alpha}$ and $\mathrm{C}=\mathrm{O}$ of Gly residues. ${ }^{7}$ (2) The precise conformational preferences of amino-acid residues depend on the character of side-chain groups, but overall stabilities of backbone conformations of Ser residue are almost similar to Ala residue ${ }^{8-11}$ (M. Oka and A. Nakajima, unpublished data). Helical conformations of poly(Ala-Gly) are theoretically analyzed by the conformational energy minimization procedure and the three-steps method which have already been used in the previous theoretical works for poly(ValPro-Gly-Gly) ${ }^{1}$ and poly(L-Ala-D-Ala). ${ }^{2}$

\section{THEORETICAL}

All conformational energy calculations were carried out with the energy functions of ECEPP, ${ }^{12}$ and minimization was continued until conformational energy did not change by more than $0.001 \mathrm{kcal} \mathrm{mol}^{-1}$ between successive iterations. During minimizations, all $\phi, \psi$, and $\chi^{1}$ for Ala and Gly residues were allowed to vary. All other backbone dihedral angles were fixed at $180^{\circ}$.

Two sets of starting conformations were used. The first set was obtained by the following method. Conformational energies of AcAla-Gly-NHMe were minimized using all combinations of single-residue minima of Ala and Gly ${ }^{13}$ as starting conformations. $(\phi, \psi)=$ $\left(-75^{\circ}, 140^{\circ}\right)$ for Ala, and $(\phi, \psi)=\left(-75^{\circ}\right.$, $\left.140^{\circ}\right)$ and $\left(75^{\circ},-140^{\circ}\right)$ for Gly were also used as single-residue minima. 69 minimum-energy conformations were obtained for dipeptide with $\Delta E<10 \mathrm{kcal} \mathrm{mol}^{-1}$. All 69 minimumenergy conformations of Ac-Ala-Gly-NHMe were used as the starting conformations of the peptide having two repeating units of Ala-Gly, i.e., Ac-(Ala-Gly $)_{2}-\mathrm{NHMe}$. During minimization, the conditions of helical conformation ${ }^{1,2}$ was used. Then, all minimum-energy conformations of Ac-(Ala-Gly) ${ }_{2}-$ NHMe $(\Delta E<10$ kcal $\left.\mathrm{mol}^{-1}\right)$ were used as the starting conformations for the minimization of conformational energy of Ac-(Ala-Gly $)_{12}-$ NHMe. Selection of the starting conformations in the first set is based on the hierarchy of interactions in peptide, polypeptide and protein systems. ${ }^{1,2}$ The second set was selected by the following method. Conformational energy of Ac-(Ala-Gly $)_{12}-\mathrm{NHMe}$ was calculated by changing $\phi_{\mathrm{Ala}}$ and $\psi_{\mathrm{Ala}}$ at $15^{\circ}$ intervals and fixing $\left(\phi_{\mathrm{Gly}}, \psi_{\mathrm{Gly}}\right)$ to the energy minima of Ac-Gly-NHMe (i.e., $\left(83^{\circ},-76^{\circ}\right),\left(-83^{\circ}, 76^{\circ}\right)$, $\left(180^{\circ}, 180^{\circ}\right),\left(173^{\circ},-62^{\circ}\right),\left(-173^{\circ}, 62^{\circ}\right),\left(72^{\circ}\right.$, $\left.53^{\circ}\right)$, and $\left(-72^{\circ},-53^{\circ}\right)$ ), and fixing $x_{\mathrm{Ala}}^{1}=60^{\circ}$ and all other dihedral angles to $180^{\circ} .37$ local minima in $\left(\phi_{\mathrm{Ala}}, \psi_{\mathrm{Ala}}\right)$ space were selected as starting conformations. Energy minimizations were carried out for all conformations in the above two starting-conformation sets with the condition of helical conformation. ${ }^{1,2}$

A bend (occuring at $i+1$ and $i+2$ th residues) is defined as a conformation in which $R \leqq 7 \AA$ ( $R$ is the distance between $i$ th $\mathrm{C}^{\alpha}$ and $i+3$ th $C^{\alpha}$ atoms.) and also classified into eleven types given in Table I of ref 14. A polar hydrogen atom and an oxygen or nitrogen atom with an interatomic distance of less than $2.3 \AA$ are regarded to be hydrogen-bonded. Conformational space is divided into 16 regions with the conformational letter codes as shown in Figure 1 of ref 13. The conformational energy per whole molecule, $\Delta E$, is defined by $\Delta E=E-E_{0}$, where $E_{0}$ is the value of $E$ at the global minimum on the potential energy surface of the particular molecules, and $\Delta E_{\text {res }}$ is defined by $\Delta E_{\mathrm{res}}=\Delta E / m$, where $m$ is number of residues 
Table I. Calculated minimum energy conformations ${ }^{\mathrm{a}}$ of Ac-(Ala-Gly) ${ }_{12}-\mathrm{NHMe}$

\begin{tabular}{|c|c|c|c|c|c|c|c|c|}
\hline $\begin{array}{c}\text { Conformational } \\
\text { letter } \\
\text { code }\end{array}$ & $\begin{array}{c}\Delta E_{\mathrm{res}}^{\mathrm{b}} \\
\mathrm{kcal} \mathrm{mol}^{-1}\end{array}$ & $\begin{array}{l}\text { Helix }^{c} \\
\text { type }\end{array}$ & $n^{\mathrm{d}}$ & $h^{\mathrm{e}}$ & $\phi_{\text {Ala }}$ & $\psi_{\mathrm{Ala}}$ & $\phi_{\mathrm{Gly}}$ & $\psi_{\mathrm{Gly}}$ \\
\hline A A & 0.00 & $\alpha \quad(\mathrm{R})$ & 3.64 & 1.47 & -66 & -41 & -65 & -42 \\
\hline $\mathrm{D} \mathrm{C}^{*}$ & 0.58 & $\beta^{4.6}(\mathrm{~L})$ & 4.64 & 1.20 & -145 & 71 & 83 & -72 \\
\hline$A^{*} A^{*}$ & 0.74 & $\alpha \quad(L)$ & 3.61 & 1.49 & 55 & 47 & 61 & 46 \\
\hline$C E^{*}$ & 0.90 & $\beta^{6.2}(\mathrm{~L})$ & 6.25 & 0.71 & -87 & 70 & 163 & -177 \\
\hline$C D^{*}$ & 1.20 & $\beta^{4.6}(\mathrm{R})$ & 4.65 & 1.21 & -87 & 67 & 164 & -80 \\
\hline $\mathrm{E} \mathrm{C}^{*}$ & 1.38 & $\beta^{5.3}$ (L) & 5.34 & 0.91 & -164 & 130 & 74 & -79 \\
\hline A $\mathrm{H}$ & 1.45 & $\beta^{5.3}(\mathrm{~L})$ & 5.30 & 0.98 & -87 & -61 & -90 & -117 \\
\hline $\mathrm{C} \mathrm{C} \mathrm{C}^{*}$ & 1.70 & $\beta^{4.7}(\mathrm{R})$ & 4.68 & 1.42 & -72 & 110 & 98 & -65 \\
\hline E C & 1.98 & $\beta^{10.3}(\mathrm{~L})$ & 10.32 & 0.56 & -151 & 134 & -83 & 77 \\
\hline $\mathrm{A}^{*} \mathrm{H}^{*}$ & 1.99 & $\beta^{5.2}(\mathrm{R})$ & 5.20 & 0.96 & 55 & 74 & 116 & 110 \\
\hline G D & 2.17 & $\beta^{4.7}(\mathrm{R})$ & 4.70 & 1.09 & -161 & -67 & -116 & 50 \\
\hline A $\mathrm{H}$ & 2.23 & $\beta^{5.0}(\mathrm{~L})$ & 4.99 & 1.14 & -78 & -37 & -156 & -103 \\
\hline F A & 2.49 & $\beta^{6.8}(\mathrm{~L})$ & 6.75 & 1.00 & -76 & 165 & -65 & -37 \\
\hline
\end{tabular}

a All minima with $\Delta E_{\mathrm{res}}<2.5 \mathrm{kcal} \mathrm{mol}^{-1}$.

b $E_{0}=-3.78 \mathrm{kcal} \mathrm{mol}^{-1} . \Delta E_{\mathrm{res}}=\left(E-E_{0}\right) / 24$.

c Helix sence is abbreviated as $\mathrm{R}$ or L for right- or left-hand, respectively.

d Number of residues per turn.

e Rise per residue.

of a molecule. The $\beta$-helix is the helix which has a spiral structure with $x$ residues per turn. Two helical parameters, $n$ and $h$, are the number of residues per turn and rise per residue, respectively.

\section{RESULTS}

Stable Conformations of Ac- $(\text { Ala }- \text { Gly })_{2}-$ NHMe

A total of 48 energy minima of Ac-(AlaGly) ${ }_{2}-\mathrm{NHMe}$ was found in $\Delta E<10 \mathrm{kcal}$ $\mathrm{mol}^{-1}$. The lowest-energy conformation is AA conformation with $\left(\phi_{\mathrm{Ala}}, \psi_{\mathrm{Ala}}, \phi_{\mathrm{Gly}}, \psi_{\mathrm{Gly}}\right)=$ $\left(-67^{\circ},-41^{\circ},-67^{\circ},-40^{\circ}\right)$. This conformation was obtained from the 23th low-energy conformation of Ac-Ala-Gly- NHMe, that is $\mathrm{AA}\left(-69^{\circ},-43^{\circ},-70^{\circ},-44^{\circ}\right)$ and $\Delta E=1.59$ $\mathrm{kcal} \mathrm{mol}^{-1}$. Differences of backbone conformations between dipeptide and tetrapeptide are small. This indicates that AA conformation is stabilized by the inter-residue interactions in tetrapeptide. The second low-energy conformation of Ac- $(\mathrm{Ala}-\mathrm{Gly})_{2}-\mathrm{NHMe}$ is $\mathrm{CC}^{*}\left(-93^{\circ}\right.$, $69^{\circ}, 73^{\circ},-97^{\circ}$ ) with $\Delta E=0.51 \mathrm{kcl} \mathrm{mol}^{-1}$. It was obtained from the lowest-energy conformation of Ac-Ala-Gly-NHMe with CC* $\left(-83^{\circ}, 80^{\circ}, 83^{\circ},-75^{\circ}\right)$ and the 15 th low-energy conformation with $\mathrm{CF}^{*}\left(-84^{\circ}\right.$, $\left.77^{\circ}, 75^{\circ},-154^{\circ}\right)$ and $\Delta E=1.18 \mathrm{kcal} \mathrm{mol}^{-1}$, respectively. These results indicate that the low-energy conformations stabilized by the short-range interactions change their conformations by the additional further range interactions and also change their relative stabilities as shown in the theoretical conformational analysis of poly(L-Ala-D-Ala). ${ }^{2}$

Local Minima in $\left(\phi_{\mathrm{Ala}}, \psi_{\mathrm{Ala}}\right)$ Maps of Ac- $(\text { Ala-Gly })_{12}-$ NHMe for the Specified Backbone Conformation of Gly Residue

Four typical $(\phi, \psi)$ maps of Ala residue of Ac-(Ala-Gly $)_{12}-\mathrm{NHMe}$ with the specified values of $\left(\phi_{\mathrm{Gly}}, \psi_{\mathrm{Gly}}\right)=\left(-72^{\circ},-53^{\circ}\right),\left(72^{\circ}\right.$, $\left.53^{\circ}\right),\left(-83^{\circ}, 76^{\circ}\right)$, and $\left(83^{\circ},-76^{\circ}\right)$ under the conditions of helical conformation are shown in Figures 1a, 1b, 1c, and 1d, respectively. Contour lines of Ala residue are represented 


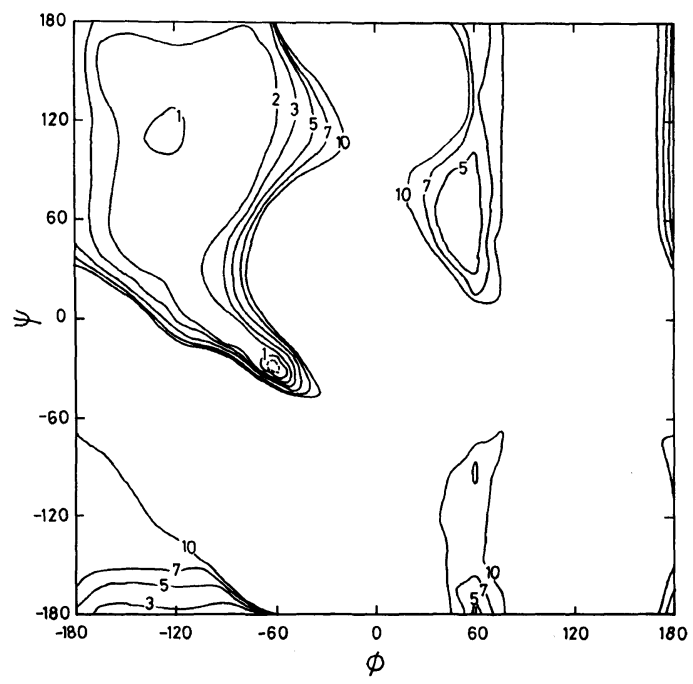

(a) $\left(\phi_{\text {Gly }}, \psi_{\text {Gly }}\right)=\left(-72^{\circ},-53^{\circ}\right)$, $E_{\text {min }}=12.37 \mathrm{kcal} \mathrm{mol}^{-1}$

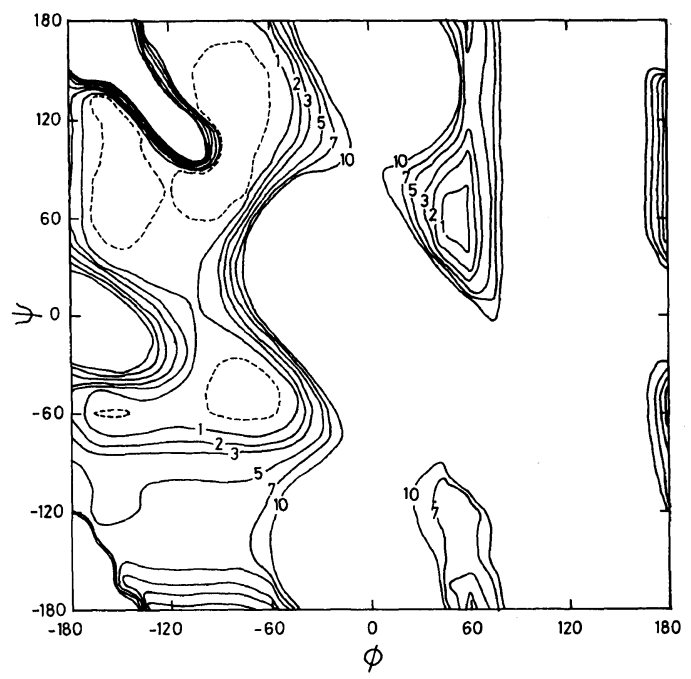

(c) $\left(\phi_{\text {Gly }}, \psi_{\text {Gly }}\right)=\left(-83^{\circ}, 76^{\circ}\right)$, $E_{\min }=52.17 \mathrm{kcal} \mathrm{mol}^{-1}$

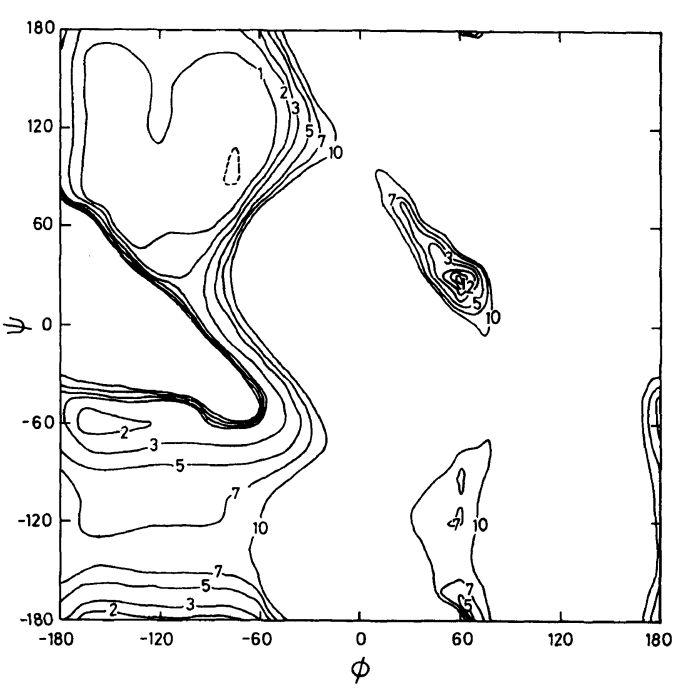

(b) $\left(\phi_{\text {Gly }}, \psi_{\text {Gly }}\right)=\left(72^{\circ}, 53^{\circ}\right)$, $E_{\min }=37.48 \mathrm{kcal} \mathrm{mol}^{-1}$

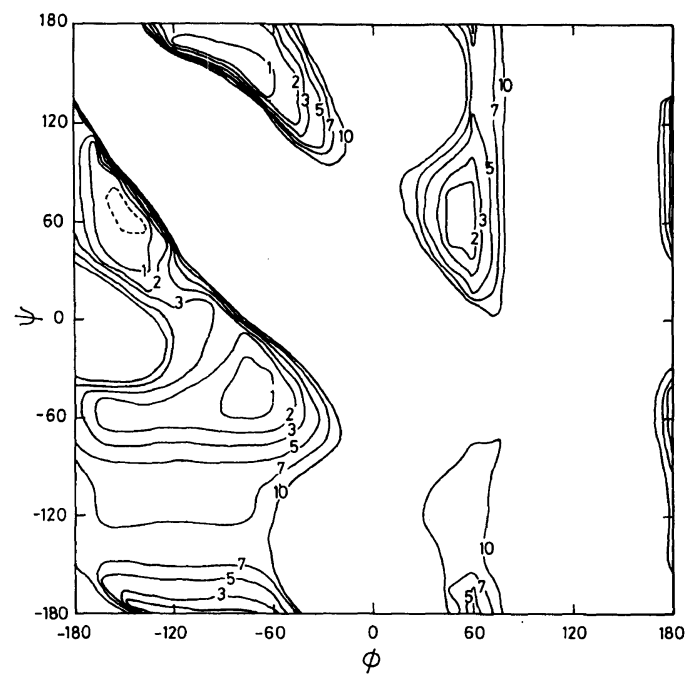

(d) $\left(\phi_{\mathrm{Gly}}, \psi_{\mathrm{Gly}}\right)=\left(83^{\circ},-76^{\circ}\right)$, $E_{\min }=22.74 \mathrm{kcal} \mathrm{mol}^{-1}$

Figure 1. Energy contour $(\phi, \psi)$ maps of Ala residue of Ac-(Ala-Gly) $)_{12}-$ NHMe at $15^{\circ}$ intervals for the specified $(\phi, \psi)$ of Gly residue with the condition of helical conformation and fixed $\chi_{\mathrm{Ala}}^{1}=60^{\circ} . E_{\min }$ is the minimum energy in each map.

by the energy difference from the lowest-energy in each $(\phi, \psi)$ map, and energy difference is also designated as the value per residue. Stable conformational regions in $(\phi, \psi)$ maps are restricted to more narrow regions than those of Ac-Ala-NHMe, and several conformations which are energetically favorable for AcAla-Gly-NHMe are destabilized because of the atomic overlaps in helical conformations. For example, EC* conformation is a stable 
conformation for Ac-Ala-Gly-NHMe (the 7th low-energy conformation with $\Delta E=0.59$ $\mathrm{kcal} \mathrm{mol}^{-1}$ ). However, as shown in Figure 1d, most of $E$ conformational region of Ala residue in Ac- $(\text { Ala-Gly })_{12}-\mathrm{NHMe}$ is unstable region for the case of $\left(\phi_{\mathrm{Gly}}, \psi_{\mathrm{Gly}}\right)=\left(83^{\circ},-76^{\circ}\right)$. Because the Gly residue lacks a methyl group in side chain, the degree of restriction caused by Gly residue is not so significant as that caused by $\mathrm{D}-\mathrm{Ala}$ residue in Ac-(L-Ala-DAla $)_{12}-\mathrm{NHMe}^{2}$. For example, as shown in Figure $1 \mathrm{a}$, the region around $\left(\phi_{\mathrm{Ala}}, \psi_{\mathrm{Ala}}\right)=$ $\left(-90^{\circ}, 90^{\circ}\right)$ for $\left(\phi_{\mathrm{Gly}}, \psi_{\mathrm{Gly}}\right)=\left(-72^{\circ},-53^{\circ}\right)$ is low-energy regions, but corresponding region for Ac-(L-Ala-D-Ala $)_{12}-\mathrm{NHMe}$ is unstable one. Similar stable regions were also found in Figurs $1 \mathrm{~b}$ and $1 \mathrm{~d}$.

The global minimum conformation for the $15^{\circ}$ grid is right-handed $\alpha$-helical conformation with $\left(\phi_{\mathrm{Ala}}, \psi_{\mathrm{Ala}}, \phi_{\mathrm{Gly}}, \psi_{\mathrm{Gly}}\right)=\left(-60^{\circ},-30^{\circ}\right.$, $\left.-72^{\circ},-53^{\circ}\right)$. The second low-energy conformation in $15^{\circ}$ grid was found at $\left(-135^{\circ}\right.$, $60^{\circ}, 83^{\circ},-76^{\circ}$ ) with $\Delta E_{\text {res }}=0.43 \mathrm{kcal} \mathrm{mol}^{-1}$. This conformation is the left-handed $\beta^{4.4}$. helical conformation composed of successive bends at Ala-Gly and Gly-Ala portions. As already mentioned in the THEORETICAL section, 37 minima found in the $\left(\phi_{\mathrm{Ala}}, \phi_{\mathrm{Ala}}, \psi_{\mathrm{Gly}}, \phi_{\mathrm{Gly}}\right)$ space were used as the starting conformations of energy minimization of Ac-(Ala-Gly) ${ }_{12}-$ NHMe.

\section{Stable Conformations of Ac- $(\text { Ala-Gly })_{12}$ NHMe}

In Table I, all stable conformations of Ac-(Ala-Gly $)_{12}-\mathrm{NHMe}$ with $\Delta E_{\text {res }}<2.5 \mathrm{kcal}$ $\mathrm{mol}^{-1}$ are shown. The lowest-energy conformation is a right-handed $\alpha$-helical conformation (AA conformation) with $\left(\phi_{\mathrm{Ala}}, \psi_{\mathrm{Ala}}\right.$, $\left.\phi_{\mathrm{Gly}}, \psi_{\mathrm{Gly}}\right)=\left(-66^{\circ},-41^{\circ},-65^{\circ},-42^{\circ}\right)$, and a left-handed $\alpha$-helical conformation (A*A* conformation) with $\left(55^{\circ}, 47^{\circ}, 61^{\circ}, 46^{\circ}\right)$ is found as the 3 rd low-energy conformation. Backbone conformation of the right-handed $\alpha$-helix of Ac-(Ala-Gly $)_{12}-\mathrm{NHMe}$ almost corresponds to that of the AA cofnormation of Ac-(Ala-
Gly) ${ }_{2}$ NHMe. Moreover, the difference of conformation energy between the starting and final conformation at the third step of minimizations is small (i.e., $0.02 \mathrm{kcal} \mathrm{mol}^{-1}$ per residue). Similar results were also obtained for the left-handed $\alpha$-helix. These results indicate that $\alpha$-helical conformation is essentially stabilized by interactions between two repeatunits (i.e., tetrapeptide), and corresponds to the results that right- and left-handed $\alpha$-helical conformations exist in the deep energetical well in the conformational space as shown in Figures $1 \mathrm{a}$ and $1 \mathrm{~b}$.

The second low-energy conformation is DC* with $\left(-145^{\circ}, 71^{\circ}, 83^{\circ},-72^{\circ}\right)$ and $\Delta E_{\mathrm{res}}=0.58 \mathrm{kcal} \mathrm{mol}^{-1}$ as shown in Figure 2 . This conformation is a left-handed $\beta^{4.6}$-helix composed of consecutive bend conformations, i.e., type IV bend at Ala-Gly and Gly-Ala dipeptide sequences. Two type hydrogen bonds are formed at $\left(\mathrm{Ala}_{i}\right) \mathrm{CO} \cdots \mathrm{HN}\left(\mathrm{Ala}_{i+1}\right)$ and $\left(\mathrm{Ala}_{i}\right) \mathrm{CO} \cdots \mathrm{HN}\left(\mathrm{Gly}_{i+2}\right)$, and Gly CO is exposed to the outside of helix. Two DC* conformations with $\left(-146^{\circ}, 91^{\circ}, 84^{\circ},-75^{\circ}\right)$ and $\left(-144^{\circ}, 72^{\circ}, 83^{\circ},-72^{\circ}\right)$ are found as the 5 and 6 th low-energy conformations $\left(\Delta E_{\mathrm{res}}=0.54\right.$ and $\left.0.57 \mathrm{kcal} \mathrm{mol}^{-1}\right)$ of Ac(Ala-Gly) $)_{2}-\mathrm{NHMe}$, respectively. These two conformations slightly shifted to $\beta^{4.6}$-helix with additional further range interactions. Moreover, CC* (the 2nd low-energy conformation with $\left(-93^{\circ}, 69^{\circ}, 73^{\circ},-97^{\circ}\right)$ and $\Delta E_{\mathrm{res}}=0.13 \mathrm{kcal} \mathrm{mol}^{-1}$ ) and $\mathrm{DF}^{*}$ (the $34 \mathrm{th}$ one with $\left(-152^{\circ}, 63^{\circ}, 73^{\circ},-150^{\circ}\right)$ and $\Delta E_{\text {res }}=$ $1.61 \mathrm{kcal} \mathrm{mol}^{-1}$ ) conformations of Ac-(AlaGly) ${ }_{2}-\mathrm{NHMe}$ are also transformed to DC* conformation $\left(\beta^{4.6}\right.$-helix). As in the case of $\alpha$-helix, backbone conformation of the $\beta^{4.6}$ helix of Ac-(Ala-Gly) ${ }_{12}-\mathrm{NHMe}$ almost corresponds to that of the 6th low-energy conformation (DC*) of Ac-(Ala-Gly) ${ }_{2}-$ $\mathrm{NHMe}$, and conformational energy difference between starting and final conformations at the third step of minimizations is also small (i.e., $0.01 \mathrm{kcal} \mathrm{mol}^{-1}$ per residue). That is, the $\beta^{4.6}$-helix is essentially stabilized by interac- 

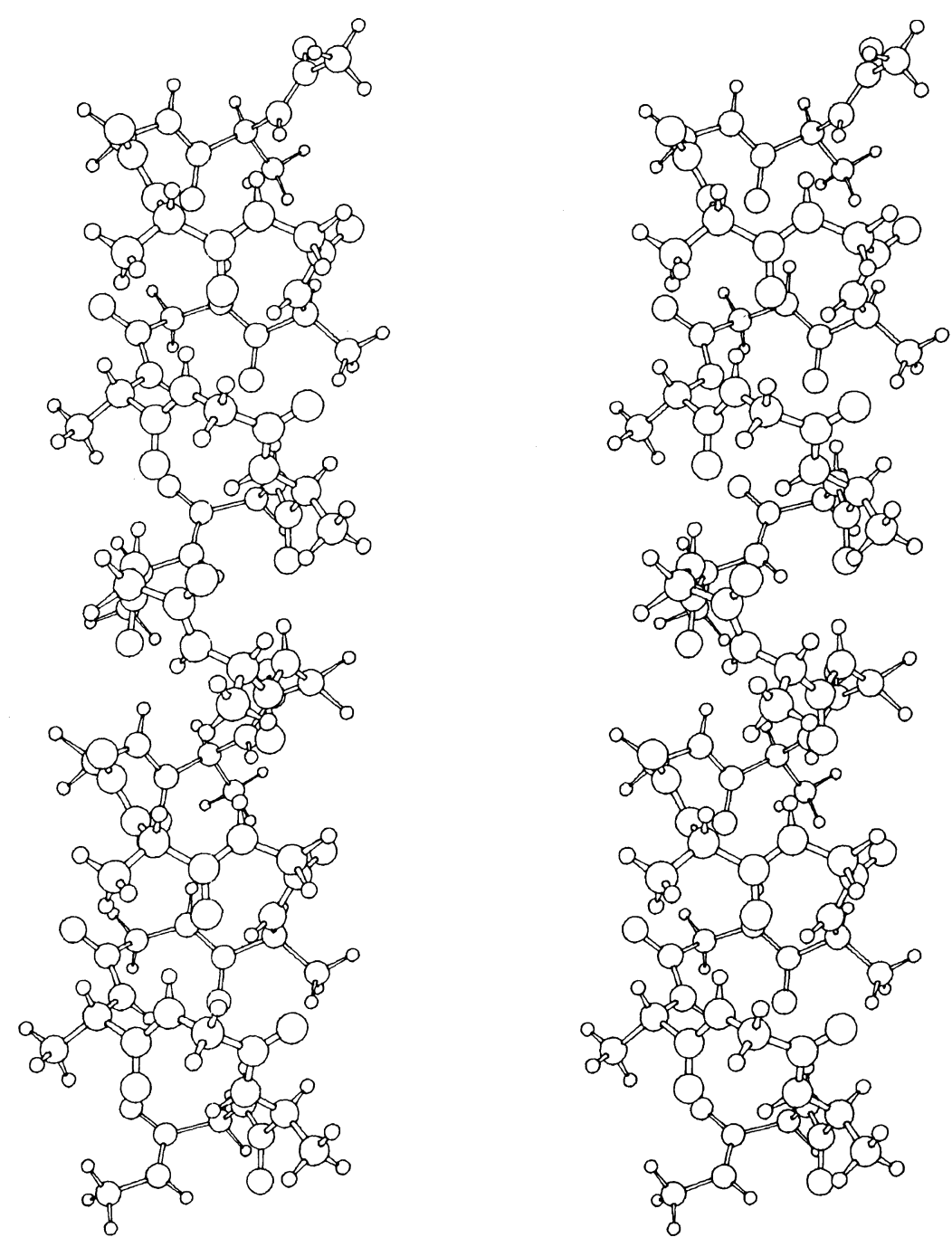

Figure 2. Left-handed $\beta^{4.6}$-helical conformation with the second low-energy $\Delta E_{\text {res }}=0.58 \mathrm{kcal} \mathrm{mol}^{-1}$. The $\phi$ and $\psi$ of Ala and Gly residues are $\left(-145^{\circ}, 71^{\circ}, 83^{\circ},-72^{\circ}\right)$ and corresponding conformational letter code is $\mathrm{DC}^{*}$.

tions between two repeat-units of Ala-Gly sequence. However, the existence of $\mathrm{CC}^{*}, \mathrm{DF}^{*}$ and another $\mathrm{DC}^{*}$ conformations, which shifted to the backbone conformation of $\beta^{4.6}$-helix with the further range interactions, indicates that the pathways to the energetical minimum corresponding to the $\beta^{4.6}$-helix exist in the conformational space. $\mathrm{CD}^{*}$ conformation is found as the 5 th low-energy conformation with $\Delta E_{\mathrm{res}}=1.20 \mathrm{kcal} \mathrm{mol}^{-1}$, however, this con- formation with $\left(-87^{\circ}, 67^{\circ}, 164^{\circ},-80^{\circ}\right)$ is not a complete enantiomer of above DC* conformation. This is different from the result that $\mathrm{CD}^{*}$ and DC* conformations of poly(L-Ala-DAla) are completely enantiomeric, i.e., their backbone conformations are $\left(-83^{\circ}, 72^{\circ}, 153^{\circ}\right.$, $\left.-75^{\circ}\right)$ and $\left(-152^{\circ}, 75^{\circ}, 83^{\circ},-72^{\circ}\right)$, respectively.

The 4th low-energy conformation $\left(\mathrm{CE}^{*}\right)$ is a left-handed $\beta^{6.2}$-helical conformation with 


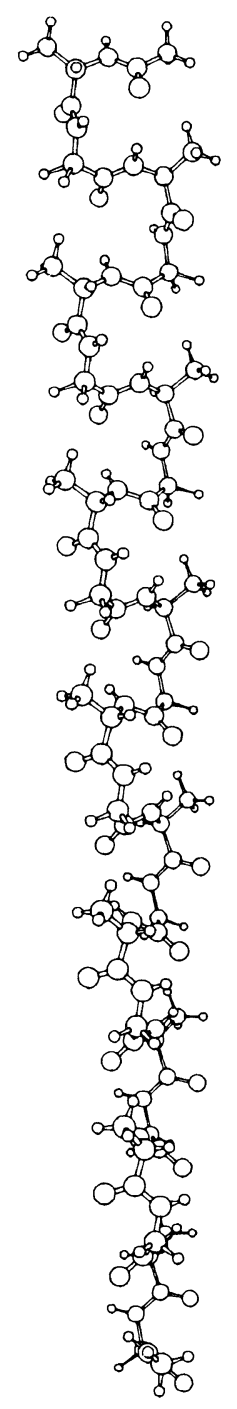

(a) $\mathrm{CA}^{*}$ conformation with $\Delta E_{\mathrm{res}}=2.52 \mathrm{kcal} \mathrm{mol}^{-1}$ and $\left(-70^{\circ}, 103^{\circ}, 75^{\circ}, 42^{\circ}\right)$

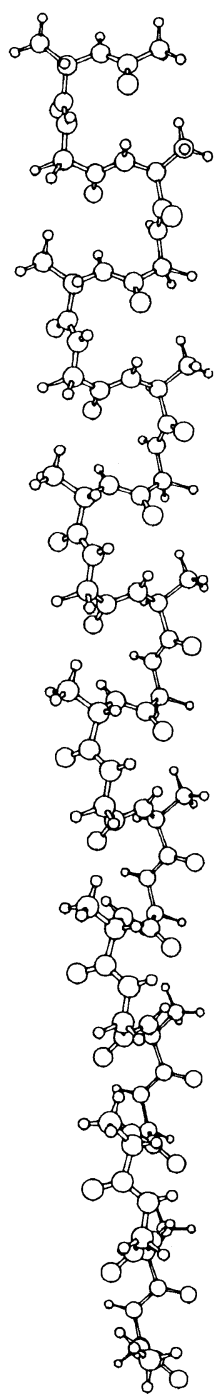

Figure 3. Helical conformations related to the proposed silk I structures.

$\left(-87^{\circ}, 70^{\circ}, 163^{\circ},-177^{\circ}\right)$ and $\Delta E_{\text {res }}=0.90$ $\mathrm{kcal} \mathrm{mol}{ }^{-1}$. This $\beta^{6.2}$-helix is very similar to the $\beta^{6.2}$-helix with $\left(-97^{\circ}, 76^{\circ}, 159^{\circ},-168^{\circ}\right)$ which is the 3 rd low-energy helical conformation of poly(L-Ala-D-Ala) (see Figure $2 \mathrm{~b}$ of ref 2.) However, $\Delta E_{\mathrm{res}}=0.19 \mathrm{kcal} \mathrm{mol}^{-1}$ of the latter helix is smaller than $0.90 \mathrm{kcal} \mathrm{mol}^{-1}$ of $\beta^{6.2}$-helix in this work. All other helices from the 6 to 13th helical conformations $(1.37<$ (b) $\mathrm{EA}^{*}$ conformation with $\Delta E_{\mathrm{res}}=3.29 \mathrm{kcal} \mathrm{mol}^{-1}$ and $\left(-154^{\circ}, 153^{\circ}, 70^{\circ}, 52^{\circ}\right)$
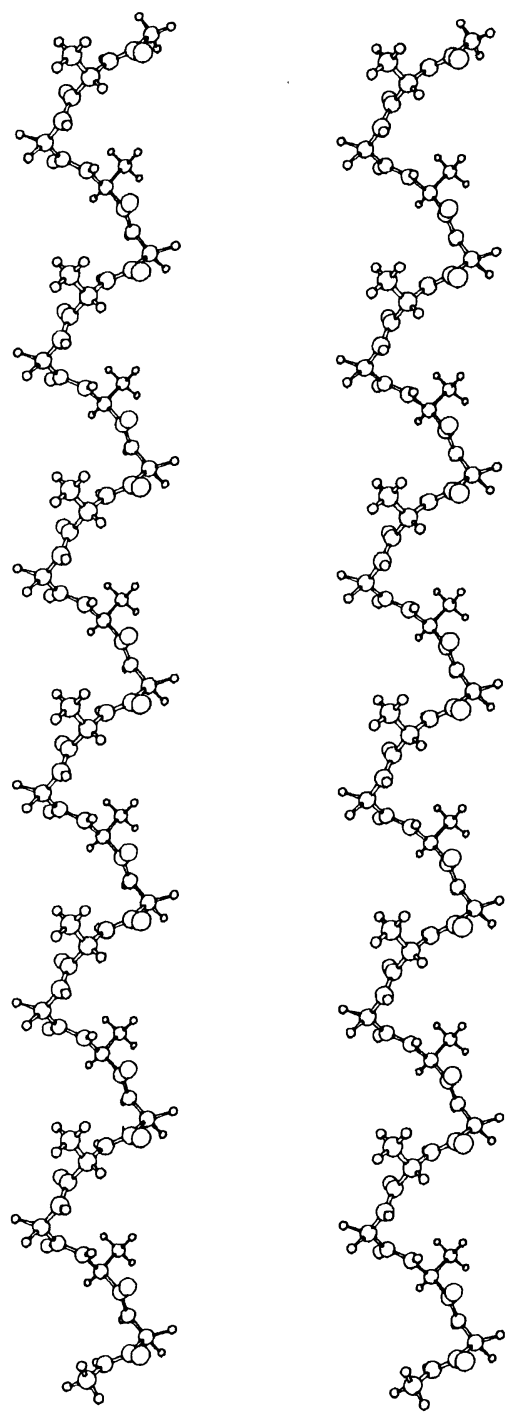

$\Delta E_{\mathrm{res}}<2.50 \mathrm{kcal} \mathrm{mol}^{-1}$ ) are $\beta$-helices having different number of residues per turn.

Three helices composed of bend structure were found at $\Delta E_{\mathrm{res}} \simeq 2.5 \mathrm{kcal} \mathrm{mol}^{-1}$. $\mathrm{CA}^{*}$ conformation $\left(-70^{\circ}, 103^{\circ}, 75^{\circ}, 42^{\circ}\right)$ at $\Delta E_{\text {res }}=$ $2.52 \mathrm{kcal} \mathrm{mol}^{-1}$ has type II bend at Ala-Gly portion (Figure $3 \mathrm{a}$ ), and two $\mathrm{AC}^{*}$ conformations, $\left(-71^{\circ},-41^{\circ}, 82^{\circ},-75^{\circ}\right)$ at $\Delta E_{\mathrm{res}}=$ $2.55 \mathrm{kcal} \mathrm{mol}^{-1}$ and $\left(-77^{\circ},-40^{\circ}, 69^{\circ},-98^{\circ}\right)$ 
at $\Delta E_{\mathrm{res}}=2.58 \mathrm{kcal} \mathrm{mol}^{-1}$ have type $\mathrm{II}^{\prime}$ bend at Gly-Ala portion. These three helices can be considered as a specieal case of $\gamma$-helix found for poly(Val-Pro-Gly-Gly) ${ }^{1}$ in the sense that their basic structures are non-spiral conformations.

Several helical conformations, related to the proposed conformations as silk I structure of Bombyx mori silk fibroin, ${ }^{15-19}$ were also found, i.e., CA* (Figure 3a), EA* (Figure 3b), $\mathrm{DA}, \mathrm{DD}$, and $\mathrm{AA}^{*}$ conformations with $\Delta E_{\text {res }}=2.52,3.29,3.33,3.62$, and $4.05 \mathrm{kcal}$ $\mathrm{mol}^{-1}$, respectively. Moreover, several conformations having reasonable values of $n$ and $h$ as silk I model conformation were also found (ex., GC, EA, and AE conformations with $\Delta E_{\mathrm{res}}=3.04,3.12$, and $3.54 \mathrm{kcal} \mathrm{mol}^{-1}$, respectively).

\section{DISCUSSIONS}

Several models ${ }^{15-19}$ were proposed for silk I structure of Bombyx mori silk fibroin. A crankshaft model was proposed by Lotz and Keith ${ }^{15}$ using selected-area electron diffraction and X-ray diffraction for small lamellar crystals prepared from aqueous $\mathrm{LiBr}$ solution of poly(Ala-Gly). The backbone conformation of this model is $\left(\phi_{\mathrm{Ala}}, \psi_{\mathrm{Ala}}, \phi_{\mathrm{Gly}}, \psi_{\mathrm{Gly}}\right)=\left(-123^{\circ}\right.$, $\left.122^{\circ}, 57^{\circ}, 72^{\circ}\right)$. Similar conformation was found in the calculated energy minima at $\Delta E_{\mathrm{res}}=3.29 \mathrm{kcal} \mathrm{mol}^{-1}$ as $\mathrm{EA}^{*}$ conformation with $\left(-154^{\circ}, 153^{\circ}, 70^{\circ}, 52^{\circ}\right)$. As shown in Figure $3 \mathrm{~b}, \mathrm{EA}^{*}$ conformation has no intramolecular hydrogen bonds, and all $-\mathrm{NH}$ and - CO groups are exposed to the outside of helix. This conformation has helical parameters $n=4.01$ and $h=2.53$ which are closed to those of Lotz and Keith ( $n=4$ and $h=2.4)$. Asakura and Yamaguchi proposed three models ${ }^{17}$ on the basis of the ${ }^{13} \mathrm{C} \mathrm{CP} / \mathrm{MAS}$ NMR data, ${ }^{7,20} \mathrm{X}$-ray diffraction data. ${ }^{16}$ Backbone dihedral angles of their models $\mathrm{A}\left(-150^{\circ}, 50^{\circ}\right.$, $\left.145^{\circ}, 75^{\circ}\right), \mathrm{B}\left(-145^{\circ}, 90^{\circ},-85^{\circ},-45^{\circ}\right)$, and $\mathrm{C}\left(-150^{\circ}, 70^{\circ}, 80^{\circ},-135^{\circ}\right)$ correspond to those of the calculated energy minima, DD $\left(-151^{\circ}, 70^{\circ},-178^{\circ}, 62^{\circ}\right)$ with $\Delta E_{\text {res }}=3.62$ $\mathrm{kcal} \mathrm{mol}^{-1}$, DA $\left(-142^{\circ}, 55^{\circ},-65^{\circ},-42^{\circ}\right)$ with $3.33 \mathrm{kcal} \mathrm{mol}^{-1}$, and $\mathrm{DC}^{*}\left(-145^{\circ}, 71^{\circ}\right.$, $84,-72^{\circ}$ ) with $0.58 \mathrm{kcal} \mathrm{mol}^{-1}$, respectively. The helical parameters of DD, DA and DC* conformations are $(n, h)=(3,36,2.74),(4.06$, $2.05)$, and $(4.64,1.20)$, respectively. DC* conformation is the most energetically stable on but this helix is more condensed along the helical axis than the experimentally proposed helical conformation by the favorable interunit interactions such as the hydrogen bonds $\left(\mathrm{Ala}_{i}\right) \mathrm{CO} \cdots \mathrm{NH}\left(\mathrm{Gly}_{i+2}\right)$ and $\left(\mathrm{Ala}_{i}\right) \mathrm{CO} \cdots \mathrm{H}-$ $\mathrm{N}\left(\mathrm{Ala}_{i+1}\right)$. Ichimura and Okuyama ${ }^{18}$ tried electron diffraction and X-ray powder diffraction measurements for Fcplx ${ }^{21}$ and X-ray diffraction measurement for fibroin film, and analyzed the silk I structure for the repeated amino-acid sequence of Ala-Gly. They proposed a model whose backbone conformation is $\left(-99^{\circ}, 100^{\circ}, 75^{\circ}, 63^{\circ}\right)$. It almost corresponds to our calculated $\mathrm{CA}^{*}$ conformation $\left(-70^{\circ}\right.$, $\left.103^{\circ}, 75^{\circ}, 42^{\circ}\right)$ with $\Delta E_{\mathrm{res}}=2.52 \mathrm{kcal} \mathrm{mol}^{-1}$, $n=4.18$ and $h=2.16$ (Figure 3a). An $\alpha_{\mathrm{R}} \alpha_{\mathrm{L}^{-}}$ structure (AA* conformation) was proposed by Lim and Steinberg ${ }^{19}$ with the speculation using CPK model. Their $\alpha_{\mathrm{R}} \alpha_{\mathrm{L}}$-structure is constructed by right- and left-handed $\alpha$-helical conformation for Ala and Gly residues, respectively. Calculated results showed that AA* conformation with $\left(-75^{\circ},-43^{\circ}, 73^{\circ}, 52^{\circ}\right)$ is found at $\Delta E_{\mathrm{res}}=4.05 \mathrm{kcal} \mathrm{mol}^{-1}$. That is, $\mathrm{AA}^{*}$ conformation is relatively unstable conformation with intra-molecular interactions. $\mathrm{AA}^{*}$ conformation is a right-handed $\beta^{18.4}$-helix, and all $-\mathrm{NH}$ and - $\mathrm{CO}$ groups situate inside and outside of helix, respectively. This conformation has no intra-molecular hydrogen bonds and thus is stabilized by non-bonded interactions caused by residual packing.

The values of $\Delta E_{\text {res }}$ of Ac-(Ala-Gly $)_{12-}$ NHMe which have backbone conformations corresponding to the above models, i.e., those proposed by Lotz-Keith, Asakura-Yamaguchi (models A, B, C), Ichimura-Okuyama and 
Lim-Steinberg, are 4.21, 4.00, 3.62, 3.64, 3.35, and $4.07 \mathrm{kcal} \mathrm{mol}^{-1}$. These model conformations changed to the $\mathrm{EA}^{*}\left(\Delta E_{\mathrm{res}}=3.29\right.$ $\left.\mathrm{kcal} \mathrm{mol}^{-1}\right)$, DD (3.62), DA (3.33), DC* (0.58), CA* (2.52), and AA* (4.05) conformations after their conformational energies were minimized. Among these 6 conformations, $\mathrm{CD}^{*}$ is most energetically favorable within intra-molecular interactions, however, its helical parameters $n$ and $h$ are different from those evaluated from X-ray diffraction measurements. ${ }^{15,18,22}$ From a consideration of $\Delta E_{\text {res }}$ and experimentally and theoretically evaluated helical parameters (theoretical ones are calculated from the values of $(\phi, \psi)$ at local energy-minima), EA* (corresponding to LotzKeith's model), DA (Asakura-Yamaguchi)

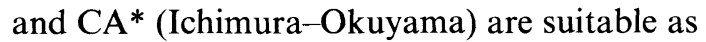
model conformations of silk I within intramolecular interactions among above six proposed conformations.

Iizuka and Yang ${ }^{23,24}$ found that the CD curve of Bombyx mori silk fibroin in water $(\mathrm{pH}$ 7.3) has a negative band at $199 \mathrm{~nm}$ which is characteristic for a coiled conformation. However, its mean residue ellipticity $[\theta]$ is smaller than those of poly(L-glutamic acid) ${ }^{25,26}$ and $\operatorname{poly}\left(N^{5}-\omega \text {-hydroxyethyl-L-glutamine }\right)^{27}$ in random-coiled conformation. Kobayashi et $a l .{ }^{28,29}$ noted that the aqueous solution of Bombyx mori silk fibroin at room temperature indicates low helix content at the concentration less than $5 \%$ and helix content increases with the increase with concentration at the concentration more than 5\% (Figure 1 of ref 28). However, the CD spectrum at the concentration of $8.6 \%$ has a broad negative band from 205 to $225 \mathrm{~nm}$ which is different from those of Antheraea pernyi silk fibroin showing the typical CD spectrum of $\alpha$-helix. ${ }^{29}$ The CD spectrum of Bombyx mori fibroin solution at the concentration less than $0.1 \%$ has a negative dichroic peaks around $195 \mathrm{~nm}$ at $5^{\circ} \mathrm{C}$, and at higher temperature, a negative dichroic peaks appeares around $215 \mathrm{~nm}$ related to the $\beta$-structure. ${ }^{29}$ The ${ }^{13} \mathrm{C}$ NMR spectram of liquid silks of Bombyx mori and Antheraea pernyi show different sharpness of signals. ${ }^{28}$ This means that the helical conformations of Bombyx mori and Antheraea pernyi differ in mobility. Moreover, Asakura et al. measured the ${ }^{13} \mathrm{C}$ NMR spectra of the silk gland of intact Bombyx mori and in regenerated aqueous fibroin solution, ${ }^{30,31}$ and showed that there is no $\alpha$-helical portion in the silk fibroin stored in the middle silk gland of Bombyx mori and that the helix detected in the Bombyx mori silk fibroin solution is the silk I type rather than the $\alpha$-helical type.

The above experimental results indicate that silk fibroin can take several stable helical conformations depending on the given external conditions. The multifariousness of helical conformations found in silk fibroin corresponds to the existence of conformational ensemble composed of many stable helical conformations as shown in this work.

\section{REFERENCES}

1. M. Oka, Y. Baba, A. Kagemoto, and A. Nakajima, Polym. J., submitted.

2. M. Oka, Y. Baba, A. Kagemoto, and A. Nakajima, Polym. J., 22, 135 (1990).

3. R. D. B. Fraser and T. P. McRae, "Conformation in Fibrous Proteins and Related Synthetic Polypeptides," Academic Press, New York, 1973.

4. N. Hojo, Ed., "Zoku Kenshi-no Kozo," Shinshu University, Ueda, 1980.

5. K. Hirabayashi, K. Uchiyama, H. Ishikawa, and Y. Go, Sen-i Gakkaishi, 23, 538 (1967).

6. K. Hirabayashi, H. Ishikawa, M. Kakudo, and Y. Go, Sen-i Gakkaishi, 24, 397 (1968).

7. H. Saito, R. Tabeta, T. Asakura, Y. Iwanaga, A. Shoji, T. Ozaki, and I. Ando, Macromolecules, 17, 1405 (1984).

8. M. Oka and A. Nakajima, Polym. J., 16, 693 (1984).

9. M. Oka, T. Hayashi, and A. Nakajima, Polym. J., 17, 621 (1985).

10. M. Oka, Y. Baba, A. Kagemoto, and A. Nakajima, Polym. Bull., 21, 377 (1989).

11. M. Oka, Y. Baba, A. Kagemoto, and A. Nakajima, Polym. Bull., 21, 385 (1989).

12. F. A. Momany, R. F. McGuire, A. W. Burgess, and H. A. Scheraga, J. Phys. Chem., 79, 2361 (1975).

13. S. S. Zimmerman, M. S. Pottle, G. Nemethy, and H. A. Scheraga, Macromolecules, 10, 1 (1977). 
14. S. S. Zimmerman and H. A. Scheraga, Biopolymers, 16, 811 (1977).

15. B. Lotz and H. D. Keith, J. Mol. Biol., 61, 201 (1971).

16. B. Lotz and F. Colonna-Cesari, Biochimie, 61, 205 (1979).

17. T. Asakura and T. Yamaguchi, J. Seric. Sci. Jpn, 56, 300 (1987).

18. S. Ichimura and K. Okuyama, Polym. Prep. Jpn, 38, 2845 (1989).

19. V. I. Lim and S. V. Steinberg, FEBS Lett., 131, 203 (1981).

20. T. Asakura, A. Kuzuhara, R. Tabeta, and H. Saito, Macromolecules, 18, 1841 (1985).

21. T. Konishi, M. Kondo, and M. Kurokawa, Sen- $i$ Gakkaishi, 23, 64 (1967).

22. T. Konishi and M. Kurokawa, Sen-i Gakkaishi, 24, 550 (1968).

23. E. lizuka and J. T. Yang, Proc. Natl. Acad. Sci. USA,
55, 1175 (1966).

24. E. Iizuka and J. T. Yang, Biochemistry, 7, 2218(1968).

25. G. Holzwarth and P. Doty, J. Amer. Chem. Soc., 87, 218 (1965).

26. A. J. Alder, R. Hoving, J. Potter, M. Wells, and G. D. Fasman, J. Am. Chem. Soc., 90, 4736 (1968).

27. W. L. Mattice, J. Lo, and L. Mandelkern, Macromolecules, 5, 729 (1972).

28. Y. Kobayashi, T. Fujiwara, Y. Kyogoku, K. Kataoka, Abstracts of Papers, the 19th Meeting of Nuclear Magnetic Resonance, Japan (1980), p 149.

29. A. Kataoka, Y. Kobayashi, T. Fujiwara, and Y. Kyogoku, Abstracts of Papers, in 1981 International Society of Non-mulberry Silks, (1981), p 71.

30. T. Asakura, H. Suzuki, and Y. Watanabe, Macromolecules, 16, 1024 (1983).

31. T. Asakura, Y. Watanabe, A. Uchida, and $\mathbf{H}$. Minagawa, Macromolecules, 17, 1075 (1984). 